\section{Thorax: the lean and slippered Pantaloon years}

\author{
Andrew Bush, ${ }^{1}$ lan Pavord ${ }^{2}$
}

Having sadly run out of Adrian Mole book titles, we move from the Prostate Years to Shakespeare's sixth age of manand by this time next year, with our successors in place, we will truly be in our second childishness and mere oblivion, sans teeth, sans eyes, sans taste (not a lot to lose there), sans everything-although perhaps our detractors will say we are in the seventh age already. So this will be our last New Year message, but not our last fling-as with our predecessors, we will be writing a final valedictory editorial in the summer, but unlike them, we will use it to pay off old scores. 'We have a little list'-aka the Sir Arthur Sullivan's Major General-wait and see if you are on it, and be afraid, be very, very afraid.

This has been another good year for Thorax. The impact factor, that perennial Aunt Sally which we all hate but have to live with (like Ministers of Health?) has risen again to 8.562, and we continue to have a stream of excellent submissions sent to us. Those who know us best will know it is not of our doing, and the credit

${ }^{1}$ National Heart and Lung Institute, Imperial College, London, London, UK; ${ }^{2}$ Nuffield Department of Medicine, University of Oxford, Oxford, UK

Correspondence to Professor Andrew Bush, National Heart and Lung Institute, Imperial College, London, London, UK; a.bush@imperial.ac.uk belongs elsewhere. So let us now praise famous men and women, and their parents who begat them. First up are the Thorax publication team-Claire, Allison, Aimee, Emma and many more, and especially Joe, our long-suffering editorial assistant. Their efficiency has only been surpassed by their patience and good humour, as ever more unreasonable requests with ever more ridiculous deadlines are sent to them. Thanks to them, time from acceptance to on-line publication is 16 days and from acceptance to publication is 5 months. Next, our Deputy Editors-thanks to them, Hanging Committee makes Monty Python look like Fordyce's Sermons (who read them and with what result, oh literary cognoscenti? Answer at the end of the editorial), and their wisdom, hard work and above all their bizarre sense of humour has made our jobs so much easier to do, and so, so much more fun. Next, the Associate Editors-thanks to them, the average time to first decision is a staggeringly low 17 days. Thorax is NOT a slow Journalwe suggest our figures for handling manuscripts compare favourably with most others in the field, so please blow that trumpet. Of course we are sorry for the Authors who get rejected-more than $50 \%$ instant reject, more than $90 \%$ eventual reject-but we have to make priority decisions given the pages available to us.
Better luck next time, and better luck with the incoming Editorial team. Nonetheless, we would like to thank all authors, successful or otherwise, who have sent in their work. We must also credit the Editorial Board and especially the reviewers for detailed and focused advice about the manuscripts, which is greatly appreciated. Without all these dedicated people, nothing could have been achieved.

So a few months to go; we hope Thorax will continue to thrive, and we are sure we will continue to have fun. There are some cracking manuscripts coming, and planned themed cancer and ATS issues. There will be a few more editorials than usual-this does not reflect a change in policy, merely that we have had some great reviews that we thought were too good to be left on the website, and have asked the reviewer to turn it into an editorial. We remain keen to receive photos to use on the front cover. See the April 2012 and December 2014 issues for excellent examples. Please do send us potential candidates in a digital format.

And the answer to the Literary quiz? Mr Collins to the Bennet family in Pride and Prejudice, and go and read the book to find out the rest.

Competing interests None.

Provenance and peer review Not commissioned; internally peer reviewed.

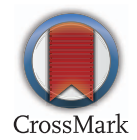

To cite Bush A, Pavord I. Thorax 2015;70:11.

Thorax 2015;70:11.

doi:10.1136/thoraxjnl-2014-206531 